\title{
ABALOS NO CORPO, A IMINÊNCIA DE UM MONSTRO? O CIBORGUE EM NEUROMANCER, DE WILLIAN GIBSON
}

George Lima (UFU)

Recebido em 27 nov 2018. George Lima é Doutorando pelo Programa de PósAprovado em 29 jan 2019. Graduação em Estudos Literários pela UFU. Possui Mestrado em Linguística pela UESB e Graduação em Letras pela UNEB. Atualmente é integrante do Grupo de Estudos sobre Epistemologia, Ética e Linguagem - UNEB e membro do PSINEMA - Corpo, Audiovisualidades e Psicanálise - UESB/USP. Os assuntos de empenho e que constituem suas investigações giram em torno de problematizações que envolvem semiose, discurso, literatura e videogame.

Resumo: No presente artigo investigamos de que modo o corpo das personagens funciona como condição de existência dos espaços que são dados a ver na obra literária Neuromancer, escrita por Willian Gibson. Por outro lado, notamos que o status dos espaços depende do corpo, que, por sua vez, é determinado por esses espaços, os quais fazem com que a esse corpo sejam associadas instâncias que fogem ao que trivialmente chamamos de natural. Nesses "entre lugares" dos espaços, vemos a iminência fantástica do corpo ciborgue, convergindo matéria orgânica com o maquínico, e, dessa forma, configura-se o que parece ser uma espécie de monstruosidade. Para realizarmos essa leitura, utilizamos algumas noções postuladas 
por Michel Foucault (2013b) em torno da literatura enquanto ser de linguagem, e outras postuladas também por Foucault (2001) e por Jacques Derrida (1971) sobre a monstruosidade de acordo com o domínio jurídico-biológico.

Palavras-chave: Ciborgue; Ciberespaço; Corpo; Neuromancer.

Abstract: In this article, we investigate how the body of characters functions as the condition of existence of spaces that are given in the literary work Neuromancer, written by Willian Gibson. On the other hand, we notice that the status of the spaces depends on the body, which, in turn, it is determined by those spaces, which make that body be associated with instances that escape what we trivially call natural. In the "space-in-between" of the spaces, there is a fantastic imminence of the cyborg body, converging with the machinist, and, in this way, what appears to be a kind of monstrosity end up configuring itself. In order to make this reading, we made use of some assumptions postulated by Michel Foucault (2013b) around literature as a being of language, and other assumptions also postulated by Foucault (2001) and Jacques Derrida (1971) in relation to monstrosity according to the legal-biological domain.

Keywords: Cyborg; Cyberspace; Body; Neuromancer.

\section{INTRODUÇÃO}

Não cessam os trabalhos que procuram informar o caráter visionário entre a novela literária Neuromancer, que fora escrita e publicada em 1984 por William Gibson, com o que temos hoje em termos de tecnologia corpo-computacional. Dessa evidência visionária foi possível extrairmos diversas proposições de estudiosos quando colocamos Neuromancer em relação ao desenvolvimento 
tecnológico que aconteceu posterior a sua escritura: 1) a obra enquanto despertadora de interesses no recém-desenvolvimento dos sistemas de interação computacional e na produção do ciberespaço (HAYWARD, 1993); 2) cyberpunk que, como outras do mesmo gênero, apresenta a construção de visões de mundos futuros do ciberespaço com toda uma vasta gama de desenvolvimentos tecnológicos e relações de luta (FEATHERSTONE \& BURROWS, 1995); 3) limiar de existência mais recente do ciborgue que aponta para formas de existência pós-corporais, do corpo orgânico em conexão com o maquínico (SANTAELLA, 2003); 4) obra noir com força do imaginário residente na descrição e sensação narrativa como ferramenta de observação da sociedade contemporânea (AMARAL, 2008); e 5) proveniência de aspectos discursivos que são vividos e materializados hoje em videogames (LIMA, 2017).

De modo sintético, o que podemos dizer a respeito dessas proposições e somar a elas é que, entre a segunda metade do século XIX e o século XXI, presenciamos um grande avanço tecnológico em termos de funcionamento e popularização do ciberespaço, . isto é, cada vez mais os computadores foram se tornando mais complexos e seus abismos de redes de conexão foram sendo povoados aos poucos, fazendo com que muitos dos aspectos materializados em Neuromancer pudessem ser desdobrados hoje por nossos corpos [de fato] como se fôssemos os próprios cowboys (hackers) dados a ver na obra.

Esse visionismo gibsoniano traz à tona no seu modo de inscrição do ciberespaço um germe do que Michel Foucault (2013a) havia pronunciado numa conferência do Círculo de Estudos Arquiteturais em Paris sobre "heterotopologia", duas décadas anteriores à 
publicação de Neuromancer. A novela de Gibson materializa com precisão na sua superfície de inscrição um tipo específico de relação entre espaços bem semelhante ao que Foucault propôs na sua analítica dos espaços durante aquela conferência. Assim, se Gibson proporcionava implicações de algo que viria a ter existência num futuro próximo, Foucault já disponibilizava de pressupostos teóricos e metodológicos para a análise desses espaços outros a que a obra gibsoniana é profética.

Convém referirmos aqui à existência de um ensaio escrito por Wesley Dalton (2014), no qual o autor se propõe fazer uma miseen-scène reflexiva mostrando como a heterotopia teorizada por Foucault (2013a) dá forma à disposição dos espaços materializados em Neuromancer. De outro modo, se não diferente a esse artigo, nosso objetivo aqui é colocarmos em cena o corpo das personagens, visto que parece imprescindível que ele seja fator determinante na constituição desses contra-espaços que o mesmo ocupa. Portanto, é pensando com Foucault que nos debruçamos na análise de Neuromancer, investigando a maneira pela qual os corpos das personagens da obra são determinantes na constituição do ciberespaço.

Por outro lado, vemos que não só o status dos espaços depende do corpo, como também este corpo é determinado por esses espaços, fazendo com que a ele sejam associadas instâncias que fogem do que trivialmente chamamos de natural, tipo de ritual de entrada ou chave de entrada para se estar nesses espaços. Ainda aí veremos aparecer um corpo fantástico em sua iminência, convergindo matéria orgânica com o maquínico e, dessa forma, configura-se o que parece ser uma espécie de 
monstruosidade. Fantástico e monstruoso porque traz para a sua existência e para a sua morfologia a transgressão de leis num domínio jurídico-biológico.

\section{LITERATURA E CONSTITUIÇÃO DOS ESPAÇOS}

O primeiro aspecto da obra gibsoniana a que damos atenção aqui é a singularidade constitutiva dos espaços que aparecem na obra. O fato desses espaços funcionarem como base constitutiva para todos outros aspectos que aparecem e contornam a obra gibsoniana se torna o motivo pelo qual damos essa atenção a priori. A matrix, ou o ciberespaço (ciberspace), mostra-se como ponto central na constituição desses espaços que aparecem na obra, tendo uma construção própria e, pelo que se sabe, sendo pela primeira vez utilizada e empregada de forma definida no curso da história.

De acordo com Mike Featherstone e Roger Burrows (1995, p.5), o termo ciberespaço é genericamente tomado como um conjunto de tecnologias que tem em comum a capacidade de simular ambientes nos quais humanos podem interagir. No entanto, diferentemente desta concepção genericamente utilizada pelos teóricos da comunicação, o ciberespaço em Neuromancer designa um universo de redes digitais, o qual se torna terreno de encontros e aventuras, lugar dos próprios conflitos bélicos e de relações corporativas, não funcionando necessariamente apenas como simulação. A própria obra descreve:

(1) A matrix tem suas raízes em games de fliperama primitivos [...]. Ciberespaço. Uma alucinação consensual vivenciada diariamente por bilhões de operadores autorizados, em todas as nações, 
por crianças que estão aprendendo conceitos matemáticos... uma representação gráfica de dados abstraídos dos bancos de todos os computadores do sistema humano. Uma complexidade impensável. Linhas de luz alinhadas no não espaço da mente, aglomerados e constelações de dados. Como luzes da cidade, se afastando... (GIBSON, 2008, p.77)

Afastando-se da imagem genérica de ciberespaço, a obra gibsoniana constrói a matrix de modo que possamos entendê-la enquanto um espaço que, embora vivido e tocado, é formado por elementos abstratos intácteis. Contudo, embora não conversando entre si em termos de sentido, essas duas construções de ciberespaço têm em comum o uso de um discurso que separa e une, contraditoriamente, em termos foucautianos, o espaço físicoconcreto do espaço intáctil-virtual para criar as bases materiais da matrix de computadores e de videogames/fliperamas.

Observamos que essa separação instaurada por esse discurso se dá no nível da duplicação que caracteriza a própria obra literária, isto é, o discurso vai se materializar no próprio exercício da linguagem literária, que se caracteriza por exercer certa autonomia ao obliterar a referência e a produção de sentido, voltando-se a si mesma numa espécie de autorrepresentação. Isso retoma o que Foucault (2013b) escreveu sobre o caráter ontológico da literatura: a escrita literária significando não a coisa, mas a própria palavra, a literatura se aprofundando na impalpável densidade da sua autorrepresentação para ser o que ela pretende ser. Assim, o uso metodológico das palavras "autorrepresentação", "reduplicação" e "espelho" se torna fundamental para compreendermos de que modo esse discurso vai se constituir no corpo da obra. 
Nesses termos, podemos compreender que há um sistema de reduplicação entre espaços, colocado pela obra gibsoniana a partir do qual o ciberespaço não pode ser compreendido como o espaço físico que caracteriza, por exemplo, a geografia táctilsensorial das ruas, vielas ou jardins que visitamos em nosso dia a dia, mas como um espaço interior de uma projeção virtual de uma tela gráfica na qual podemos, enquanto operadores de avatares, acessar informações virtualizadas que compõem o videogame/ fliperama, a internet ou, de modo geral, a matrix. Esse sistema de reduplicação é apresentado pela própria obra gibsoniana quando vemos a narração espacial dos ambientes que as personagens da obra perpassam.

O que chamamos de narração espacial dos ambientes confere um tipo de paralelismo das descrições dos espaços durante a narrativa que faz com que cada ambiente funcione como uma espécie de espelho que afirma e nega o outro [espaço] - por exemplo, o ambiente urbano em paralelismo com o espaço rural. Vejamos uma formulação de Neuromancer:

(2) Um ano ali e ele ainda sonhava com o ciberespaço, a esperança morrendo um pouco a cada noite. Todo o speed que tomou, todas as voltas que deu e as esquinas de Night City por onde passou, e ainda assim ele via a matrix em seu sono, grades brilhantes de lógica se desdobrando sobre aquele vácuo sem cor... O Sprawl ficava a um longo e estranho caminho de distância sobre o Pacífico, e ele não era mais nenhum cara do console, nenhum cowboy de ciberespaço. Apenas mais um marginal na viração. Mas os sonhos apareciam na noite japonesa como figuras de vudu eletroluminescente, e ele gritava, chorava dormindo, e acordava 
sozinho no escuro, curvado em posição fetal em sua cápsula em algum hotel-caixão, as mãos trincadas no colchonete, a espuma sintética enroscada entre os dedos, tentando alcançar o console que não estava lá. (GIBSON, 2008, p.25)

Na formulação acima, podemos observar que, além de aparecer o nome do ciberespaço, há, durante a narrativa, a descrição dos sonhos que simulam as experiências da personagem ex-hacker, Case, no ciberespaço. Notamos que essa descrição das experiências no ciberespaço está em paralelo às descrições feitas das instâncias tangíveis, isto é, temos "as grades de lógica em vácuo sem cor" e "vudu eletrolumiescente" sendo refletido por "acordar sozinho no escuro", "mãos trincadas no colchonete" e "a espuma sintética enroscada entre os dedos". Esse mesmo modo de paralelismo se repete em outros momentos da obra. Vejamos outra formulação.

(3) E agora ele se lembrava dela assim, seu rosto banhado na incansável luz dos lasers, as feições reduzidas a um código; suas bochechas banhadas em um fogo escarlate ao mesmo tempo que o Castelo do Mago queimava, a testa encharcada de azul quando Munique caiu na Guerra de Tanques, boca tocada com ouro quente enquanto um cursor deslizante tirava fagulhas da parede do desfiladeiro de um arranha-céu. Ele estava com uma tremenda parada naquela noite, levando um tijolo de cetamina de Wage para Yokohama e o dinheiro já no bolso. Saíra na chuva quente que batia no asfalto de Ninsei e saltava vapor, e de algum modo ela se destacara para ele, seu rosto entre as dezenas que estavam de cara para os consoles, perdidos no game que jogavam. (GIBSON, 2008, p.28-29) 
Agora observando esta última formulação, embora não se tratando de uma descrição de um sonho da personagem, vemos a descrição de uma lembrança vivida por Case durante sua caminhada na Ninsei. Apesar de se tratar de outro tipo de experiência, a descrição da lembrança apresenta certa repetição do paralelismo espacial no funcionamento do ciberespaço em relação à descrição do sonho, visto que põe em funcionamento o abstrato-intangível em relação ao concreto.

Ainda observando a formulação (3), notamos mais uma vez o funcionamento que põe paralelamente duas espacialidades na constituição da obra literária: a da experiência físico-concreta em relação à da experiência virtual-abstrata. Nesse segundo excerto, como podemos ver, são descritas as lembranças da experiência durante a imersão da matrix (ciberespaço) de um fliperama. Durante esta descrição, podemos observar que há a reinscrição do modo de paralelismo observado na formulação (2) analisada. Em (2), podemos visualizar as descrições das lembranças que fazem referência à jogada no videogame de modo que todas as coisas referidas sejam reduzidas a códigos e feixes de luzes, coisas um tanto quanto impalpáveis quando observamos seu paralelismo sobre as descrições das experiências fora da lembrança, como a sensação do dinheiro no bolso ou da chuva quente que batia no asfalto da Ninsei, materializando o discurso que coloca avessamente opostos o virtual-cibernético em relação ao físico-palpável.

Em Neuromancer as formulações das descrições físicas funcionam em relação às do virtual-projetado. Nessa medida, o espaço físico está reduplicado em relação ao espaço virtual de modo que se refira a si mesmo. Esta referência a si não quer dizer 
que a obra representa algo que está fora dela ou é produto de algum tipo de inferência, mas que ela é tomada como referente de si mesma na medida em que traz no seu modo de ser o recurso da reduplicação dos espaços descritos para trazer para si os limites espaciais do ciberespaço.

\section{INVÓLUCROS CORPORAIS, CORPOS CIBERNÉTICOS.}

A partir do que analisamos até então, apontamos um segundo aspecto de Neuromancer: as experiências corporais no ciberespaço. Poderíamos dizer aqui que nesta obra literária a experiência na matrix é, antes de qualquer coisa, uma experiência corporal. Esta afirmação nossa se baseia na observação de que as descrições que caracterizam tanto os espaços físicos quanto os virtuais são, antes de tudo, descrições de experiências corporais nesses espaços. Não é por acaso que afirmamos que o que é vivido pelo corpo é o que estabelece ou apaga o limiar entre o espaço físico e o espaço virtual, proporcionados pela matrix dos computadores e/ou dos videogames.

Assim sendo, o corpo funciona de acordo com o tipo de relação que se estabelece entre os espaços que aparecem no interior da obra, isto é, o paralelismo espacial é determinado e determinante para o status do corpo. Em Neuromancer, teremos pelo menos três níveis de constituição corporal a depender do relacionamento que se estabelece com os espaços. Vejamos uma formulação sobre o acesso de Case à matrix:

(4) E fluiu, floresceu para ele, um truque de origami de neon fluido, o desdobrar de sua casa sem distância, seu país, um tabuleiro de xadrez 3D transparente se estendendo até o infinito. $\mathrm{O}$ olho 
interno se abrindo para a pirâmide asteca escarlate de Eastern Seabord Fission Authority queimando para além dos cubos verdes da Mitsubishi Bank of America, e alto e bem ao longe ele viu os braços em espiral de sistemas militares, para sempre além do seu alcance.

$E$, em algum lugar, ele estava rindo, em um loft pintado de branco, dados distantes acariciando o deck, lágrimas de libertação correndo pelo rosto. (GIBSON, 2008, p.78)

Observando a formulação (4), podemos notar mais uma vez a matrix sendo caracterizada pelo aspecto virtual-abstrato na medida em que dá a ver elementos impalpáveis e imprecisos como "origami de neon fluido", "desdobrar de sua casa sem distância", "xadrez 3D transparente se estendendo até o infinito" e "braços em espiral de sistemas militares". Mas, como podemos verificar na formulação (4), além dessa visualização, notamos que todos esses elementos só são possíveis se forem olhados por um olho interno ao corpo. Essa abstração torna o olhar algo impalpável, funcionando semelhante a um fantasma ou a uma alma que habita um espaço que o autoriza a estar.

Essa nossa observação se torna mais operante quando consideramos que essas experiências corporais funcionam frente aos elementos físico-materiais que são acariciados pelos corpos que aparecem na obra. Como podemos ver na formulação (4), há uma indicação indefinida de um lugar (loft) onde o corpo "real" da personagem Case está rindo enquanto toca um deck, um aparelho utilizado para acessar o espaço virtual da matrix. O modo pelo qual a formulação (4) referencia as instâncias do domínio físico-material faz com que os corpos sejam caracterizados de acordo com os 
espaços que ocupam: um corpo interior, digamos cibernético, que percebe e ocupa as instâncias impalpáveis e fluídas do ciberespaço e, de outro lado, um corpo exterior que toca e vive as experiências físico-materiais do espaço geográfico, ou, como alguns diriam, do espaço real.

Esse mesmo sistema de papéis dos corpos será materializado de uma outra maneira no interior da obra gibsoniana. É possível ver em Neuromancer a presença também de corpos holográficos ocupando lugares físicos quando visualizados. Esses corpos são similares aos corpos carnais, porém impalpáveis. Vejamos.

(5) O concreto se inclinava em degraus até uma espécie de palco central, um círculo elevado com um ringue reluzente de equipamentos de projeção. Nenhuma luz, a não ser os hologramas que se deslocavam e piscavam sobre o ringue, reproduzindo os movimentos dos dois homens abaixo. [...] Cores refletidas fluíam pelas lentes de Molly enquanto os homens andavam em círculos pelo ringue. Os hologramas eram magnificações à potência de dez; nessa escala, as facas que seguravam tinham pouco menos de um metro de comprimento. (GIBSON, 2008, p.61)

Em Neuromancer, o corpo holográfico é um corpo numérico produzido por algoritmos que o dão potência de tamanho na projeção, usando como base os corpos carnais que são refletidos, ou seja, ser projetado não é a mesma coisa que estar de fato num lugar concreto. Essa diferença é o parâmetro de constituição dos corpos que aparecem na obra. Como podemos visualizar, as projeções figuradas no interior da obra são chamadas de hologramas e também colocadas de modo que as encaramos enquanto luzes. Isso 
significa que o que temos enquanto corpo em termos de holografia são reflexos do que temos enquanto corpo carnal. Pode-se dizer aqui que as representações holográficas dos corpos carnais que foram simulados representam a si mesmas, na medida em que são colocadas em relação aos corpos carnais na obra gibsoniana. Isso quer dizer que os parâmetros de diferenciação e de relação entre os corpos holográficos e carnais são estabelecidos na medida em que vemos operar as marcas sensório-perceptivas do corpo. Esses parâmetros separam e põem em relação ao corpo do/no espaço físico-concreto com o corpo do/no espaço intáctil-virtual.

Descrever essa reduplicação entre os corpos não pretende funcionar como forma de taxionomia dos tipos de corpos que aparecem. Esse parâmetro aponta a dificuldade ou, mais precisamente, a impossibilidade de localizarmos os limiares que separam de fato o corpo virtual, uma vez que são interdependentes. Os corpos aí são o parâmetro de separação e relação, mas eles próprios são também os que dificultam esse limiar. Isso nos leva a apontar uma outra configuração para o corpo presente também na obra. Vejamos mais uma formulação:

(6) Ele colocou a bandana de tecido atoalhado preto na testa, tomando cuidado para não perturbar os dermatrodos Sendai. Ficou olhando para o deck no seu colo, mas não estava vendo de verdade; o que ele via era a vitrine daquela loja na Ninsei, o shuriken de cromo queimando com o neon refletido. (GIBSON, 2008, p.77)

Observando a formulação (6), podemos ver pistas de que o corpo da personagem Case sempre está plugado a um deck por meio de dermatrodos, espécie de condutor plugado ao cérebro, 
sobre a pele, para conexão com o ciberespaço. Ver a vitrine da loja da Ninsei e o shuriken de cromo queimando não se trata de algo que está presentificado no espaço físico da obra, são efeitos virtuais do olhar de Case no ciberespaço. Os dermatrodos são a chave no espaço físico para projeção do corpo no ciberespaço e, neste caso, o corpo de Case está tanto no lugar físico quanto no ciberespaço.

Levando em conta esses aspectos, o que vemos aparecer na obra é a representação da ausência do corpo no ciberespaço. No caso específico da matrix, vemos uma função específica do corpo a partir das ações ocorridas no ciberespaço. As ações do corpo na matrix é o parâmetro de caracterização, de diferenciação, de relação e de instauração do espaço virtual da matrix. Isso quer dizer que o corpo no ciberespaço funciona mais precisamente enquanto um espelho em que a personagem pode vivenciar e ser visto em um lugar onde ela não está, um lugar irreal que se abre virtualmente através da superfície corporal no ciberespaço. Os sujeitos responsáveis pela projeção do corpo estão lá, no lugar onde ele não está. Por essa razão é que vemos na formulação (4) a referência indefinida do corpo físico de Case acariciando um deck, uma vez que ele está num lugar distante e próximo ao mesmo tempo, no qual a personagem não está. Vemos aí a instauração do espelho como marca constitutiva do corpo cibernético e da obra literária como um todo. O entendimento desse espelho fica mais visível ao observarmos Case acessar o corpo de Molly na obra:

(7) Não faço ideia. Apenas sei que estou preparando a Moll para um gato de transmissão, então provavelmente irá acessar o sensório dela. 
- o Finlandês coçou o queixo. - agora você vai descobrir como aquelas calças dela são apertadas, hein? (GIBSON, 2008, p.79)

(8) O salto abrupto para dentro de outra carne. A matrix sumiu, uma onda de som e de cor... ela estava passando por uma rua lotada, passando por barracas vendendo software de desconto, preços escritos a caneta hidrográfica em folhas de plástico, fragmentos de música vindo de infinitos alto-falantes. Cheiro de urina, monômeros livres, perfume, krill frito. Por alguns segundos assustadores, ele lutou sem conseguir evitar o impulso de controlar o corpo dela. Depois, se forçou para assumir o estado de passividade, e tornou-se o passageiro atrás dos olhos dela. (GIBSON, 2008, p.81)

Os limites estabelecidos entre os corpos são perdidos à medida em que os vemos se ocupando mutuamente, como reflexos um do outro. O aparecimento de um corpo plugado mostra que há impossibilidade de separarmos o virtual do físico. Molly é uma espécie de ciborgue, união entre computador e corpo orgânico, que substituiu seus olhos por placas metálicas que aprimoraram sua visão. Como podemos ver nas formulações (7) e (8), Molly é acessada por Case, a partir da qual Case vê Molly, mas também, antes de qualquer coisa, vê-se em Molly. Todas as sensações visuais, olfativas e sonoras vivenciadas pelo corpo de Molly são vivenciadas também por Case. Molly aí funciona como uma espécie de avatar de Case a partir do qual ele vivencia um espaço, ou melhor, um corpo que não é o dele de fato. Molly é a representação de um corpo paradoxalmente ocupado e não ocupado por uma personagem. Ontologicamente é improvável separar o corpo cibernético de sua 
presença material na obra gibsoniana, pois mantém relação com sua exterioridade.

\section{ABALOS NO CORPO, A IMINÊNCIA DE UM MONSTRO?}

A natureza do corpo de Molly coloca em questão outras propriedades que fogem da pretensa naturalidade que constitui o corpo humano. Essas propriedades parecem dotar o corpo dessa personagem de capacidades que vão além do humano. Isso se dá de tal modo que permite por vezes que outros corpos o naveguem, operando como uma espécie de computador. Assim sendo, tornase pertinente compreendermos de que modo a personagem Molly se constitui na obra. Vejamos:

(9) Ela balançou a cabeça em negativa. Ele percebeu que as lentes eram implantadas cirurgicamente, fechando as cavidades de seus olhos. As lentes de prata pareciam brotar da pele branquinha e macia sobre as maçãs do rosto, emolduradas por cabelos pretos cortados de modo selvagem. Os dedos fechados ao redor da pistola de dardos eram compridos, brancos e com unhas pintadas de bardo. As unhas pareciam artificiais. (GIBSON, 2008, p.48)

(10) Ela estendeu as mãos com as palmas viradas para cima, os dedos brancos ligeiramente abertos, e, com um clique ligeiramente audível, dez lâminas de bisturi dupla face de quatro centímetros deslizaram de dentro de suas bainhas embaixo das unhas bordô.

Ela sorriu. As lâminas se recolheram lentamente. (GIBSON, 2008, p.49)

Como descrevemos anteriormente, Molly é uma espécie de ciborgue que implantou lentes metálicas no lugar de seus olhos 
para aprimorar sua visão. Além disso, o corpo dela é constituído por lâminas na cavidade abaixo das unhas, que funcionam como espécie de arma. Natural e sintético, orgânico e inorgânico, essa personagem converge um corpo, que no nosso imaginário é formado de músculo e sangue, com elementos que não fazem parte dessa natureza, conferindo a esse corpo um status a priori paradoxal.

Essa descrição feita em torno da personagem Molly nos lembra da perplexidade, da angústia e do medo de desmembramento do corpo humano, uma vez que parece improvável que lentes possam brotar da pele de alguém ao fechar uma cavidade que deveria ser preenchida por olhos, ou que lâminas de bisturi possam simplesmente sair por entre as unhas e a carne dos dedos. Isto é, a existência de Molly abre uma fenda no imaginário real do corpo humano, pois sujeita o natural do corpo, topia implacável, que é o contrário de uma utopia, este corpo feito de músculos e veias, corpo que está sujeito a feridas e aos desígnios do espaço-tempo.

Ainda hoje, no século XXI, depois de termos alcançado diversos avanços no que diz respeito tanto à inteligência artificial quanto à biotecnologia, um corpo como o de Molly é improvável quando relacionamos a obra com sua exterioridade, e só pode acontecer na arte, lugar do improvável e da transgressão por excelência. Toda essa convergência de elementos sintéticos e não-orgânicos no corpo o torna insólito na medida em que carrega consigo e desperta em quem o lê o inverossímil, o incômodo, o infame, o incongruente, o impossível, o incorrigível, o incrível, o inusitado e o informal.

A princípio, a explicação a que nos amparamos ao observar esse modo corporal é a de que se trata de uma anomalia no sentido de 
que foge à normalidade. E de fato o é, de modo que utilizamos um parâmetro jurídico para avaliar sua composição. Jurídico porque segue uma norma que autoriza ou veta. Claro que isso num sentido lato de jurídico. Esse parâmetro jurídico opera de acordo com o que Foucault (2001) chamou de "monstro humano": é na lei que se pode referenciar o monstro, pois o que o define é a razão dele constituir, na sua existência e em sua morfologia, não só uma violação das leis sociais, como também uma violação das leis da natureza.

Considerando de prontidão os abalos ao corpo conjurados a partir da observação do corpo de Molly, notamos que o caráter convergente e paradoxal desse corpo o coloca frente à lei natural que constitui o corpo humano. Isso acontece na medida em que viola a integridade biológica ao unir atributos artificiais e inorgânicos que não têm nada a ver com o imaginário de corpo humano real.

Por outro lado, se seguirmos a esteira da noção de monstro humano teorizado por Foucault (2001), essa mesma configuração corporal, por não corresponder à lei jurídico-biológico, colocarse-á também fora desse domínio jurídico-biológico, armando uma espécie de arapuca para a lei, pondo-se na exterioridade dela. Ao colocar-se fora desse domínio, veremos que esses abalos causados à noção de corpo não a comprometem inteiramente, constituindo uma espécie natural de contra-natureza. Isso quer dizer que o corpo de Molly pode também fugir dessa configuração monstruosa na medida em que contraditoriamente se coloca fora das leis jurídico-biológicas. Isso nos leva a uma outra explicação para a composição corporal, uma explicação que se aproxima do que Jacques Derrida postulou: 
E digo estas palavras com os olhos dirigidos, é certo, para as operações da procriação; mas também para aqueles que, numa sociedade da qual não me excluo, os desviam perante $o$ ainda inominável que se anuncia e que só pode fazê-lo, como é necessário cada vez que se efetua um nascimento, sob a espécie da não-espécie, sob a forma informe, muda, infante e terrificante da monstruosidade. (1971, p.249)

Quando algo novo surge ou nasce, quando esse algo ainda não teve tempo de ser nomeado, a tendência é de que cause estranheza quanto a sua natureza, fazendo com que o tomemos como uma espécie de monstruosidade terrificante e, assim sendo, tememos qualquer contato direto. Deslocando essa noção para compreendermos o corpo de Molly, vemos que não se torna tão terrificante assim a configuração biosintética do ciborgue frente ao seu status ainda recente e não totalmente compreendido. Ainda mais hoje quando a aparente naturalidade do corpo humano se encontra constantemente questionada pelas diversas vertentes não só das ciências biotecnológicas, mas também das ciências humanas e da linguagem. Nesse sentido, o corpo ciborgue é só mais um em mil e uma possibilidades para a obra literária.

\section{CONSIDERAÇÕES FINAIS}

Observando os espaços que constituem a obra literária, encontramos modos de colocar o corpo no jogo de espelho posto pela própria obra, levando-nos a pensar sobre a natureza corporal, isto é, os modos de viver a partir de um corpo que se tem no momento e no lugar em que possui existência: um corpo fundamental, que é muito mais da ordem do vir a ser da literatura que do natural, 
um corpo insólito que perde a equívoca naturalidade e a evidência aparente quando é colocado em relação à sua exterioridade, um corpo que tem uma materialidade movediça, instável, e que ganha visibilidade quando é colocado no jogo das relações.

Em Neuromancer notamos que o ciberespaço (ou matrix) é produto do modo de ser da literatura que tem como parâmetro a reduplicação que separa e une, ao mesmo tempo, o físico-concreto com o intáctil-virtual. Nesses termos, pode-se compreender que há uma relação de diferenciação entre espaços colocados pela novela gibsoniana a partir da qual o ciberespaço, por assim dizer, não pode ser compreendido como espaço físico ocupado pelo sujeito, mas como espaço interior de uma projeção virtual.

Ainda, vimos que a experiência na matrix é, primeiro, uma experiência corporal. Esta afirmação nossa se baseia na observação de que as descrições que caracterizam tanto os espaços físicos quanto os virtuais são, antes de tudo, descrições de experiências corporais nesses espaços. Essa experiência vivida pelo corpo é o que estabelece ou apaga o limiar entre o espaço físico e o espaço virtual, proporcionados pela matrix na obra.

É a partir do caráter movediço desse "entre espaços" experimentado pelo corpo, que vemos surgir a natureza iminentemente monstruosa da ciborgue Molly, que surge como uma figura híbrida, convergida por instâncias paradoxalmente avessas entre si, as quais se colocam fora da normatividade instaurada pelo domínio jurídico-biológico. Molly aí não é só um monstro, mas a metáfora viva dos abalos vividos pelo corpo no limiar entre o espaço físico-orgânico e o virtual-sintético. 


\section{REFERÊNCIAS}

AMARAL, Adriana (2008). "A potência do imaginário de Neuromancer nas origens da cibercultura". In: GIBSON, William. Neuromancer. 4.ed. São Paulo: Aleph. p.313-316.

DERRIDA, Jacques (1971). "A estrutura, o signo e o jogo no discurso das ciências humanas. In: A escritura e a diferença. São Paulo: Perspectiva. p.229-249.

DALTON, Wesley (2014). "Reflected spaces: heterotopia and creation of space in William Gibson's Neuromancer". In lowa Journal of Cultural Studies, Iowa-USA, 15 (1), 36-55.

FEATHERSTONE, Mike; BURROWS, Roger (1995). "Culture of technological embodiment: an introduction". In: FEATHERSTONE, Mike; BURROWS, Roger (Ed.). Cyberspace Cyberbodies Cyberpunk. London: Sage, 1995. p.1-20.

FOUCAULT, Michel (2013a). O corpo utópico, as heterotopias. Salma Tannus Muchail (Trad.). São Paulo: n-1 Edições.

(2013b). "A linguagem ao infinito". In: MOTTA, Manuel Barros da (Org.).

Estética: literatura e pintura, música e cinema. 3.ed. Rio de Janeiro: Forense Universitária. (Ditos e Escritos, III).

(2001). "Aula de 22 de janeiro de 1975". In Os anormais: curso no Collège de France (1974-1975). Eduardo Brandão (Trad.). São Paulo: Martins Fontes. p.69-100.

GIBSON, William (2008). Neuromancer. Fábio Fernandes (Trad.). 4.ed. São Paulo: Aleph.

HAYWARD, Philip (1993) "Situating Cyberspace: the popularisation of virtual reality". In: HAYWARD, Philip; WOLLEN, Tana (ed.). Future Visions: new technologies of the screen. London: British Film Institute. p.180-204.

LIMA, George (2017). Mapeamento do jogo: política do corpo em jogos da série de games Resident Evil. 2017. 112f. Dissertação (Mestrado em Linguística) Universidade Estadual do Sudoeste da Bahia, Vitória da Conquista.

SANTAELLA, Lucia (2003). Culturas e artes do pós-humano: da cultura das mídias à cibercultura. São Paulo: Paulus. 